\title{
Replacement of tricuspid valve with homovital mitral homograft in infective endocarditis: a case report
}

\author{
Carlos-A. Mestres • José L. Pomar
}

Received: 28 October 2010 / Accepted: 27 November 2010/Published online: 27 January 2011

(C) Indian Association of Cardiovascular-Thoracic Surgeons 2011

We have read with great interest the case description by Dasarathan et al. that just appeared in the latest issue of the Journal [1]. The authors have addressed an important but uncommon problem which is the need for replacement of the tricuspid valve in the setting of infective endocarditis. They have been clever enough to use a homovital homograft as part of the donation process for heart transplantation. The follow-up at 6 months yields a competent transplanted valve.

Transplantation of the mitral valve into the tricuspid position is an old story as the authors have appropriately pointed out. We were able to deal with the problem some time ago and so far our own experience [2] and that of the others [3] confirms this as a valid alternative when the tricuspid valve has to be replaced.

In their discussion Dasarathan et al. state that “... Although the long-term outlook of this operation remains uncertain, an element of tricuspid regurgitation is well tolerated...". We agree with the authors, however we have been able to produce mid- and some long-term follow-up.

C.-A. Mestres $(\bowtie) \cdot$ J. L. Pomar

Department of Cardiovascular Surgery, Hospital Clínico.

University of Barcelona,

Villarroel 170,

08036, Barcelona, Spain

e-mail: cmestres@clinic.ub.es
At 6 years with a median follow-up of five, neither calcification nor rupture of the homograft was detected and different degrees of tricuspid regurgitation with no clinical impact were seen on echocardiography [4]. Furthermore, we were able to perform homograft ring annuloplasty in a patient 13 years after the original operation [5] with good result. This confirms that this is a better alternative than the option of tricuspid valvulectomy without valve replacement as advocated many years ago by Arbulu et al. [5]. In any case, this latter option did save a number of lives in critically ill patients.

Acknowledgments We do thank the authors for this fine report.

\section{References}

1. Dasarathan C, Vaijyanath P, Cherian KM. Replacement of the tricuspid valve with a homovital mitral homograft in infective endocarditis: a case report. Indian J Thorac Cardiovasc Surg. 2010;26:207-9.

2. Pomar JL, Mestres CA. Tricuspid valve replacement using a mitral homograft: surgical technique and initial results. J Heart Valve Dis. 1993;2:125-8.

3. Mestres CA, Miró JM, Paré JC, Pomar JL. Six-year experience with cryopreserved mitral homografts in the treatment of tricuspid valve endocarditis in HIV-infected drug addicts. J Heart Valve Dis. 1999;8:575-7.

4. Mestres CA, Castellá M, Moreno A, Paré JC, del Río A, Azqueta M, et al. J Heart Valve Dis. 2006;15:389-91.

5. Arbulu A, Holmes RJ, Asfaw I. Surgical tretament of intractable rightsided infective endocarditis in drug addicts: 25 years'experience. J Heart Valve Dis. 1993;2:129-37. 